\title{
Adsorption Properties of Carbon Sorbents Based on Carbonized Peat
}

\author{
Natalia K. Kitaeva, Ekaterina A. Bannova, Maria V. Alekseeva, \\ Sergei M. Merkov and Natalia S. Ilicheva
}

Obninsk Centre for Science and Technology, 4, Gorky str., Obninsk, Kaluga region, Russian Federation, 249033.

DOI: http://dx.doi.org/10.13005/bbra/1916

(Received: 05 October 2015; accepted: 06 November 2015)

\begin{abstract}
Adsorption properties of carbon sorbents obtained by a peat microwave carbonization have been studied. It has been established that as a result of carbonization, the sorbent capacity of carbon sorbents for iodine increases significantly, while for methylene blue and for methane yellow it decreases. The carbon sorbent obtained by microwave carbonization of peat is characterized by low moisture content, high buoyancy and oil sorbent capacity, which makes it competitive among other sorbents for collecting oil and oil products.
\end{abstract}

Key words: Peat, microwave radiation, Carbonization, Carbon sorbent, Adsorption, water capacity, buoyancy, oil capacity.

Environmental pollution becomes increasingly global. Currently the world faces an urgent problem of preventing harmful impact on the nature by cleaning it from pollutants.

Oil and oil products are among the most common pollutants [Fellenberg, 1997; Kamenshikov and Bogomolny, 2005). Oil and oil products ingress into the environment is possible in a variety of conditions. The greatest amount of pollution occurs in emergency situations after spilling during transportation, in various oil extraction and processing technologies, etc.

Due to a sharp increase in the number of vehicles worldwide, they have become the most serious source of pollution not only with oil products, but with other highly toxic substances as well (lube oils, heavy metals, etc.). Often effluents from automotive repair facilities, parking lots, gas stations, car washes are drained into household and storm drains without treatment.

\footnotetext{
* To whom all correspondence should be addressed. Tel.: + 79307511865;

E-mail: kitaeva.natalia@gmail.com
}

Even the small amounts of contaminants contained in wastewater complicate and sometimes make impossible normal operation of treatment facilities, resulting in oil getting into the water bodies.

Besides, the accelerated development pace in oil refining, petrochemical and other industries related to carbon consumption, toughening environmental standards all over the world require the development of affordable, economical and effective means of protecting the environment from oil and oil products.

Among the various methods of water environments purification from oil, the most promising method is adsorption, which is quite effective and, in case of a multi-step process, may ensure cleaning up to any desired level (Kamenshikov and Bogomolny, 2005; Dubinin, 1932; Smirnov, 1982; Koganovsky at al., 1981, Artemov and Pinkin, 2008; Sirotkina and Novoselova, 2005). In addition, absorption purification of oil-contaminated water is virtually the only way to clean the water environment from oil products without invoking any secondary pollution, which distinguishes it from the chemical 
methods of water environments purification.

The existing adsorption methods of cleaning water environments from contamination by petroleum products are mainly based on using expensive, mostly imported adsorption materials. This entails considerable expenses for replacing used adsorption materials, due to their high cost. As a result, the rules of timely replacing used adsorption material are not observed everywhere. It is often cheaper for companies to pay environmental fines than to replace the absorption material in course of maintenance.

The sorbents intended for water purification from oil products should meet the following requirements: they should have maximum oil capacity and buoyancy, the technology of their manufacturing should be easy, they should be available and have low cost, and the resource base for their manufacturing should be sufficiently reliable.

Globally, carbon sorbents are used most widely (active or activated charcoals) for removing surface oil by direct contact, and for deep absorption purification. Carbon sorbents feature high sorbent capacity, and are more environmentally friendly, as compared to synthetic sorbents, namely, they are easy to recycle, nontoxic, and biodegradable. The main disadvantage of high-quality active coals is relatively high cost, due to complicated and lengthy process of manufacturing.

The highest quality carbon sorbents are obtained from nut shells (coconuts, seeds of some fruits). In Russia, the main raw material for obtaining carbon sorbents is solid hardwood, mainly birch (Kamenshikov and Bogomolny, 2005; Koganovsky et al, 1981; Buzaeva et al, 2010). Currently, in Russia there is a problem with both raw materials for obtaining carbon sorbents, and increase in their production volume.

The problem of obtaining carbon sorbents may be solved by expanding the resource base, for example, obtaining them from plants and natural organic materials, agricultural wastes, wood production wastes, etc.

A promising natural organic raw material for obtaining carbon sorbents may be peat, which is widely used in its original form for purification of various gaseous and liquid environments (Sirotkina and Novoselova, 2005; Bannova et al,
2013; Alferov, 2007; Glazkov and Glazkova, 2001).

This paper is aimed at studying adsorption characteristics of carbon sorbents obtained by means of peat carbonization.

\section{Literature review}

The adsorption properties of the material depend on its porous structure and the nature of its surface. In the process of absorption purification by contact of the sorbent with water containing oil, the surface of the sorbent interacts with both the molecules of water, and with the hydrocarbon molecules present in the water, and only mutual displacement of the molecules of the components that differ in the interaction energy with the surface of the sorbent leads to selective adsorption (Koganovsky et al, 1990).

Thus, effective sorbents for removing organic compounds from water, oil and oil products in particular should be hydrophobic (lyophobic) materials. In this case, mainly the dispersion forces between the molecules of hydrocarbons and the hydrophobic surface of the sorbent will be present; these forces are much stronger than the forces of the sorbent interaction with the molecules of water. As a result, the surface of the sorbent will accumulate mainly hydrocarbon molecules, resulting in selective adsorption of oil and oil products.

Thus, in order to obtain a hydrophobic carbon material, peat, which is a hydrophilic (lyophilic) substance due to the fact that it contains many polar components, should be modified by carbonization before using it as an oil sorbent.

Traditional carbon sorbents are obtained by heat treatment of carbon-containing raw materials in regenerative furnaces, where organic components are decomposed, the composition and structure of high-carbon material is changed and highly porous sorbent is formed (Plachenov et al, 1983; Hu et al, 2010; Bogayev et al, 2013; Isahak et al, 2013; Belyaev, 2000). However, obtaining carbon sorbents from vegetative and natural organic materials this way presents a number of difficulties associated mainly with low efficiency of thermal radiation on such materials, in view of their low thermal conductivity. The drawbacks of the thermal method of obtaining carbon sorbents is long duration of the process, high energy consumption, uneven heating and forming a considerable temperature gradient in the material, 
which leads to obtaining carbon sorbents with unstable properties.

Using microwave radiation for obtaining carbon sorbents from vegetative and natural organic materials has attracted great interest in the science and the industry worldwide (Deng et al, 2010; Alslaibi et al, 2013; Franca et al, 2010; Miura et al, 2004; Daniel, 2006; Daniel et al, 2011). Despite the fact that microwave radiation has been used in the military since $40^{\text {-ies }}$ of the $20^{\text {th }}$ century, it is only relatively recently that the possibility of using it for the synthesis of organic and inorganic compounds, for treating a wide range of materials, etc. was considered.

The spectral band of the electromagnetic radiation in the frequency range between $300 \mathrm{GHz}$ and $300 \mathrm{MHz}$ (wavelength $1 \mathrm{~mm}$ to $1 \mathrm{~m}$ ) is called the microwave band. Microwave radiation is a combination of two variable fields, namely the electric and the magnetic fields. Yet the primary change in the substance occurs under the influence of the alternating electric field caused by polarization of the molecules of the substance. For the most effective microwave radiation effect on substance, it should be a dielectric. In the absence of microwave radiation, the molecules of the dielectric are arranged randomly. When electric field is applied to the substance, its molecules "line up" strictly in the direction of the field lines. After that, when the direction of the electromagnetic field changes to the opposite one, the molecules of the substance turn immediately $180^{\circ}$. Therefore, when a dielectric is exposed to microwave radiation, dipole polarization is induced in it due to molecules moving in accordance with changing direction of the alternating electric field. Constant movement of molecules leads to their friction, which produces heat, and the substance is heated (Danilov, 2006; Danilov et al, 2011; Danilov et al, 2010).

In addition to dipole polarization, in dielectrics placed in an alternating electric field, there are other types of polarization: structural (displacement of the dipoles and ions in a confined space), electronic (deformation of electronic shells), low frequency (ions moving in the substance with formation of volumetric charges), ion (elastic deformation of ions), which also cause heat generation inside the dielectric.

The presence of a negligible concentration of free electrons in the dielectric causes a small conduction current. Conduction current flowing through and over its surface of the dielectric is accompanied by energy dissipation and heat generation.

The specific heat output generated in such materials depends, on the one hand, on the frequency and the intensity of the microwave field, and on the other hand, on the dielectric properties of the heated material, namely, the leakage factor and the dielectric constant, and does not depend on its thermal conductivity. The higher the field voltage is, the greater the angle of rotation of the molecules is, and the greater the frequency of the electrical current is; the more often the direction of the field changes, and the more often the molecules change their position. Increasing the voltage of the field and the frequency of the current increases the heating rate of the substance. With that, reverse temperature gradient is observed in the heated substance (the temperature inside the material is higher than on its surface). This results in almost instantaneous heating of the substance throughout its volume (Feldman, 2009).

Thus, the main difference of the heating process in the microwave field, as compared to the heating process in the thermal field, is field distribution throughout the material. In the thermal process, in the absence of airflow, the temperature field is distributed evenly in the air space that surrounds the material processed; it only penetrates through it into the material, gradually warming it up. In the microwave field, the energy of microwave radiation is converted into thermal energy only in the material, and the air surrounding it does not absorb microwave energy, and is heated only by the heat emitted by the material.

The schematic diagram of a microwave installation includes a generator of electromagnetic radiation (usually a magnetron), a waveguide, a heating chamber or cavity, ventilation and cooling system of the magnetron and the chamber, a system of protection against excessive radiation, a system of instrumentation, and controls.

A microwave installation may be a system with limited and unlimited volume. The chamber of a traditional domestic microwave oven is a volume limited by a surface made of polished metal. The microwave radiation entering the heating chamber is partially absorbed by the sample, and is partially reflected from the walls of the chamber. 
Due to the high cost of specialized microwave installations, domestic microwave ovens are most often used for experiments with microwave treatment. A domestic microwave oven operates at the frequency of $2.45 \mathrm{GHz}$.

The value of response of (heating) various materials placed in the microwave installation to the influence of microwave field depends on the presence of the molecules with a dipole moment. That is, in order to ensure effective impact of microwave radiation on the material, the latter should be a dielectric, and should have a specific set of dielectric properties. Peat is one of such materials.

Peat is a widespread caustobiolith of plant origin, a predecessor of coals genetic series. Peat reserves are significant all around the world and, in fact, are only inferior to coal reserves. The territory of Russia has over $40 \%$ of the world's reserves of peat.

Peat is an organic rock formed as a result of biochemical decomposition of marsh plants in the conditions of high water content and lack of oxygen. Peat is a colloidal-disperse system that comprises organic, mineral and water components. By its physical properties, peat is different from the most similar earth material, brown coal, in higher moisture content, looser structure, lower density, by chemical properties - by presence of many water-soluble and light-hydrolyzing organic compounds, humic acids, sugars, bitumens, hemicelluloses and celluloses (Shteen, 2011).

The content of carbon in peat ranges between $48 \%$ in mossy prehumic and $65 \%$ in highly decomposed peats. Oxygen content ranges between 24.7 and $54.2 \%$, and hydrogen content between $4.7 \%$ and $7.3 \%$. Nitrogen content depends on the type of peat, and ranges between 0.6 and $2.5 \%$ in moss peats, and between 1.3 and $3.8 \%$ in lowland peats. Sulfur content is between 0.02 and $1.2 \%$.

The mineral part of peat is insignificant, and is mainly represented by primary and secondary minerals. The share of minerals is determined by the degree of peat mineralization and its type. The elemental composition of the mineral part of peat is represented by $\mathrm{Si}, \mathrm{Ca}, \mathrm{Fe}$ and $\mathrm{Al}$ (Golovaty et al, Kopanitsa, 2007).

The microporous structure of peat is formed by amorphous products of plants decomposition. With development of peat biochemical decomposition, the share of humic substances in it increases; these substances, being hydrophilic formations that are responsible for adsorption of polar molecules of water, interact weakly with non-polar hydrocarbons (Kosov et al, 2007).

All peats, regardless of the deposit and other factors, contain groups of biologically active compounds like phenolic compounds, flavonoids, phenol carboxylic acids, tannins, coumarins and polysaccharides (Kosov et al, 2007).

Complex composition of peat, including fibrous and colloidal substances of different functional composition, and large specific area of peat ensure its high sorbent capacity and the capability of various ion exchange processes (Given et al, 1984).

Thus, peat can be considered as a "dry matter - free moisture" binary system. Then the result of the microwave radiation effect on the peat will depend on the polarity of the "dry" component of peat and on the distribution of moisture in it.

The higher the content of oxygencontaining functional groups having a significant dipole moment $(-\mathrm{OH},-\mathrm{COOH})$ is, the higher the polarity of the "dry" component of peat is. In addition, the polar functional groups contribute to retention of moisture, due to the donor-acceptor interactions, which also increases peat susceptibility to the microwave treatment.

The water present in the peat features a high dielectric constant; therefore it efficiently absorbs microwave radiation, heats up and starts evaporating rapidly. Since water inside peat is confined, excessive pressure forms when it evaporates inside the peat. Driving the gradients of temperature, pressure and concentration in one direction (from the volume of the processed material to the surface) create most favorable conditions for accelerating diffusion of the steamand-air mixture from inner layers of peat to the peripheral ones. This causes effective microwave treatment of the material with less energy consumption, and improves quality of the product. When peat is heated, chemical destruction and aromatization of the polar macromolecules contained in it also occurs, which leads to increasing the carbon content in peat and to increasing its hydrophobic properties. If, in case 
of microwave treatment, the excessive pressure of the air-and-vapor mixture inside the material exceeds the ultimate tensile strength, mechanical destruction of the material will occur, resulting in formation of microcracks in the material, and in formation of a porous structure. This is particularly important in case of using the resulting product as an adsorbent.

In Russia, several methods of obtaining peat-based absorbents of oil products have been patented (Mazlova and Arakcheeva, 1999; Spiridonov et al, 2012). The patent (Mazlova and Arakcheeva, 1999) describes the method of obtaining a carbonaceous absorbent based on heat-treated peat intended for treating industrial and domestic waste waters in order to clean them from pollutants of various nature. The patent (Spiridonov et al, 2012) proposes to use peat as part of fossil-organic composite that also contains clinoptilolite, sawdust and modifying additives (foaming agent and polyelectrolyte). The obtained absorbent is recommended for removing oil spills and oil pollution, lube oils, diesel fuel, fuel oil from the hard surface of roads, soil, aquatic areas, as well as for removing ions of heavy metals (copper, nickel, zinc, chromium) and petroleum products from natural water bodies and waste waters.

Thus, peat-based sorbents may be used for removing both natural and modified contaminants. Peat and the products of peat modification are of interest as absorbents, due to their high adsorption characteristics. The influence of microwave radiation on peat is an effective way of improving its adsorption characteristics. Compared to the classical technology of obtaining sorbents, the efficiency is due to a fundamentally different method of removing moisture from the sorbent, which is related to changing the adsorption activity. In addition, volumetric heating prevents the temperature gradient, therefore, it is more efficient and safe for peat structure, which also improves quality characteristics of the sorbents obtained by microwave radiation.

\section{MATERIALSANDMETHODS}

The study was performed on highbog peat of the moss group from the Karinskoe deposit in the Kirov region. The characteristic of peat is presented in Table 1.
Peat was carbonized in a stationary installation at the frequency of $2.45 \mathrm{GHz}$ (Fig. 1). A sample of original peat was placed in a ceramic crucible. The crucible was placed in the chamber (1) and the lid was closed. In microwave modules (2), constant magnetron power was set, and carbonization was performed for limited time. The closed crucible with carbon sorbent was cooled to room temperature in the microwave installation for $30 \mathrm{~min}$. The chamber of the microwave installation (1) has ventilation pipe (3) and a system for collecting pyrolysis gases.

Efficiency of the microwave radiation effect was assessed by weight loss by peat, which was determined gravimetrically as the ratio of the difference between the weight of the initial peat and the weight of the peat after processing to the weight of initial peat, expressed in percent.

Ash content in peat was measured in accordance with GOST 11306-83.

Nitrogen, carbon, hydrogen and oxygen contents in the samples were determined with the EURO EA 3000 elemental analyzer in accordance with the manual.

Moisture content was measured using the method of equilibrium pores bridging in stationary conditions at room temperature in accordance with GOST 24160-80. Moisture content was calculated as the ratio of moisture weight to the initial weight of the sample, expressed in per cent.

Adsorption of model indicators was studied in static mode using the method of limited volume.

Iodine concentration in the solution was determined using the titrimetric method. Concentration of methylene blue (MB) and metanil yellow (MY) was determined spectrophotometrically in accordance with GOST 4453-74, GOST 6217-74 at spectrophotometer KFK3-01 in quartz pans with the thickness of the absorbing layer of $1.0 \mathrm{~cm}$ at the wavelength of 660 to 670 and 430 to $450 \mathrm{~nm}$, respectively (Kolyshkin and Mikhailova, 1972).

Peat buoyancy was determined by the time $95-100 \%$ of the sample remaining afloat. Weighed quantity of peat $1-3 \mathrm{~g}$ was placed in a 100 $\mathrm{cm} 3$ beaker filled with distilled water. The time of sample contact with water ranged between 1 and 30 days. After this period, the sample that remained 
afloat was removed, dried in a drying cabinet at the temperature of $105^{\circ} \mathrm{C}$ until constant weight was achieved, and weighed. By the difference in weight compared to the initial weight of the sample, the amount of peat remaining afloat was calculated, expressed in per cent.

The sorbent capacity was determined using the gravimetric method by saturating it with oil products in static conditions (a mixture of lube oil and diesel fuel with the viscosity of $50 \mathrm{~mm}^{2} \mathrm{~s}^{-1}$ at $20^{\circ} \mathrm{C}$ and calculating the ratio of the weight of absorbed oil to the initial weight of the sample.

\section{RESULTSAND DISCUSSION}

As a result of the influence of microwave radiation on peat, thermal pyrolysis of organic compounds accompanied by release of pyrolysis gases occurs in the latter, thereby the composition and properties of peat change, and a system of pores is formed (Alferov, 2007).

The appearance of initial and carbonized peat is shown in Fig. 2. As can be seen from the photographs (Fig. 2), after carbonization, brown peat becomes black, which is typical for carbon

Table 1. Characteristic of peat

\begin{tabular}{|c|c|c|c|c|c|c|c|}
\hline \multicolumn{3}{|c|}{ Technical analysis } & \multicolumn{5}{|c|}{ Elemental analysis, wt. \% } \\
\hline $\mathrm{W}^{\mathrm{a}}, \%$ & $A^{d}, \%$ & $\mathrm{~V}^{\mathrm{daf}}, \%$ & $\mathrm{C}$ & $\mathrm{H}$ & $\mathrm{N}$ & $\mathrm{O}$ & S \\
\hline 10.3 & 4.0 & 66.9 & 50.0 & 5.44 & 0.48 & 39.9 & 0.111 \\
\hline
\end{tabular}

$\mathrm{W}^{\mathrm{a}}$ is analytical moisture; $\mathrm{A}^{\mathrm{d}}$ is ash content; $\mathrm{V}^{\text {daf }}$ is volatile content of substances in case of heat treatment at the temperature of up to $800{ }^{\circ} \mathrm{C}$

Table 2. Characteristic of carbonized peat

\begin{tabular}{cccccccccc}
\hline \multicolumn{3}{c}{ Technical analysis } & & \multicolumn{5}{c}{ Elemental analysis, wt. \% } \\
\cline { 1 - 2 } \cline { 5 - 7 } $\mathrm{W}^{\mathrm{a}}, \%$ & $\mathrm{~A}^{\mathrm{d}}, \%$ & $\mathrm{~V}^{\text {daf }}, \%$ & & $\mathrm{C}$ & $\mathrm{H}$ & $\mathrm{N}$ & $\mathrm{O}$ & $\mathrm{S}$ \\
\hline 11.8 & 6.3 & 37.8 & & 69.0 & & 3.73 & 1.15 & 19.4 & 0.179 \\
\hline
\end{tabular}

$\mathrm{W}^{\mathrm{a}}$ is analytical moisture; $\mathrm{A}^{\mathrm{d}}$ is ash content; $\mathrm{V}^{\text {daf }}$ is volatile content of substances in case of heat treatment at the temperature of up to $800{ }^{\circ} \mathrm{C}$

Table 3. Peat saturation capacity, buoyancy and sorbent capacity

\begin{tabular}{lccc}
\hline Type of peat & $\begin{array}{c}\text { Saturation capacity, } \\
\%\end{array}$ & $\begin{array}{c}\text { Buoyancy, } \\
\text { days }\end{array}$ & $\begin{array}{c}\text { Sorbent capacity } \\
\text { g of oil products/ } \\
\text { g of sorbent }\end{array}$ \\
\hline Initial & $20-22$ & $2-4$ & $0.8-1.1$ \\
Thermally carbonized & $6-8$ & not less than 30 & $0.4-0.45$ \\
Carbonized with the use of microwave radiation & $4-5$ & not less than 30 & $0.5-0.6$ \\
\hline
\end{tabular}

sorbents, and visually indicates an increase in carbon content in carbonized peat.

Table 2 shows the main characteristics of the carbonized peat obtained with the power of microwave radiation of $700 \mathrm{~W}$ and with the duration of carbonization of $60 \mathrm{~min}$.

As can be seen from the data in Table 2, peat carbonization results in decreased humidity, increased ash content, removal of oxygen and hydrogen, thereby increasing the carbon content. In order to study the effect of peat carbonization conditions under the action of microwave radiation on the adsorption properties, samples were prepared using various power of microwave radiation and the same time of carbonization, and samples at various time of carbonization and the same power of microwave radiation. 
Fig. 3 and 4 show the dependencies of the influence of microwave radiation power and the time of carbonization on peat's ability to absorb moisture (moisture capacity). As one can see from

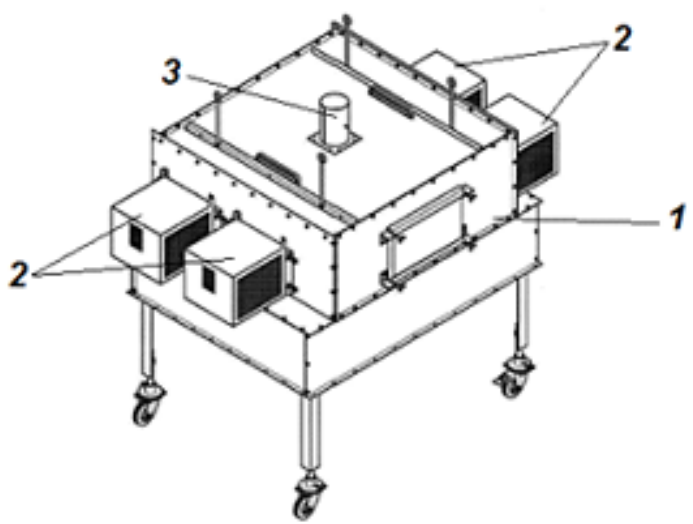

Fig. 1. Layout of a microwave installation for peat carbonization: 1 - chamber; 2 - microwave module with magnetron; 3 - vent pipe

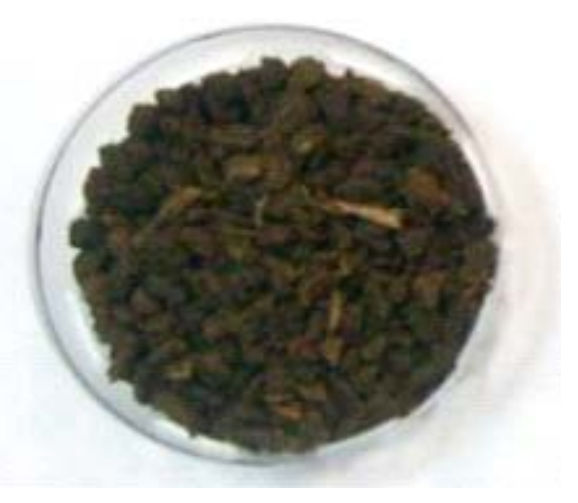

initial peat
Fig. 3 and 4, in the process of carbonization, peat's ability to absorb moisture is sharply reduced (from $20-22 \%$ to $4-5 \%$ ), as compared to the initial peat.

In order to study adsorption properties, model compounds (MB, MY, iodine) and petroleum products were used. Changes in the adsorption properties in the process of carbonization make it possible to assess the change of porosity and the degree of hydrophobic properties of carbonized peat, since hydrophobic properties of the material depend on the content of surface-active groups that can form adsorption adsorbate-sorbent complexes.

From the data in Fig. 5 and 6, one can see that the power of the microwave radiation and the duration of its influence on peat symbatically affect peat's sorbent capacity for MB, MY and iodine: sorbent capacity for MY decreases practically to 0 , for $\mathrm{MB}$, it decreases more than 2 times, and for iodine it increases almost 2 times.

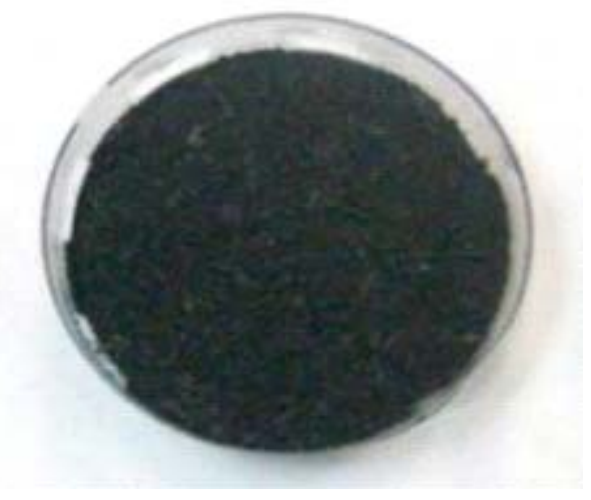

carbonized peat

Fig. 2. Appearance of initial and carbonized peats

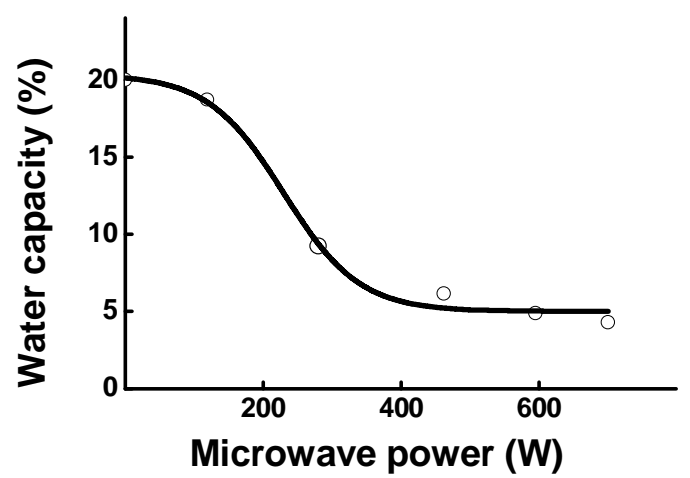

Fig. 3. Dependence of peat's maximum water capacity on the power of microwave radiation. The duration of carbonization is $60 \mathrm{~min}$

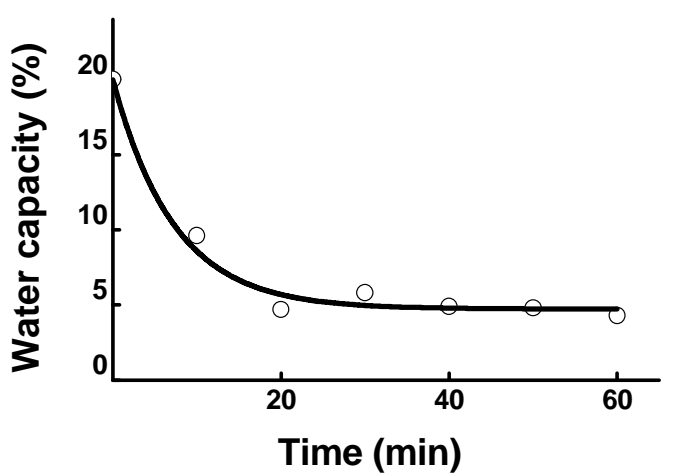

Fig. 4. Dependence of peat's maximum water capacity on the duration of carbonization. The power of microwave radiation is $700 \mathrm{~W}$ 
This difference in peat's sorbent capacity for MB, MY, and iodine is associated with the change in its porosity, and hydrophilic-lipophilic balance of the surface during the carbonization process. It is known that molecules of MB of iodine are adsorbed mainly in the meso- and micropores (MB in pores with the size of $1.5 \mathrm{~nm}$ and more, iodine - in pores $1.0 \mathrm{~nm}$ and more) (Dubinin, 1932; Balankin et al, 2004); MB molecules are predominantly adsorbed on acidic surface centers,

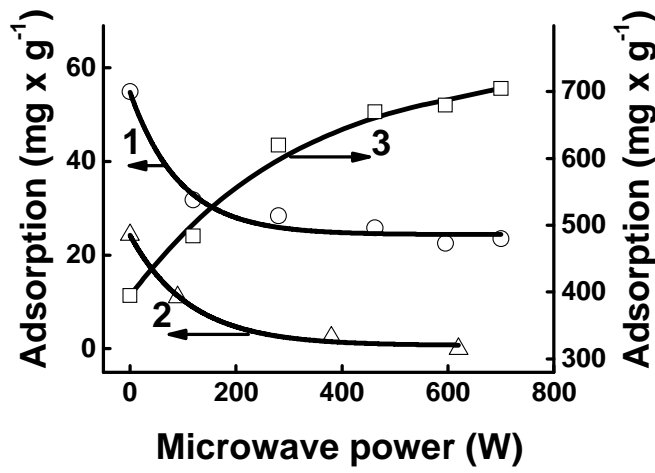

Fig. 5. Dependence of sorbent capacity for MB (1), MY (2) and iodine (3) on the power of microwave radiation

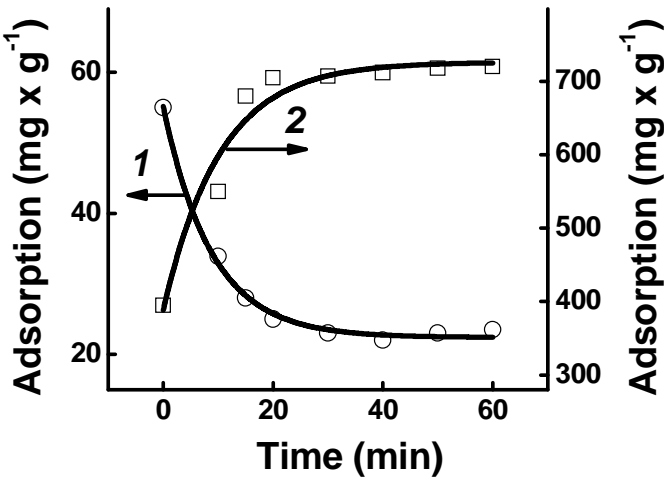

Fig. 6. Dependence of the sorbent capacity for MB (1) and iodine (2) on the duration of carbonization. The power of microwave radiation is $700 \mathrm{~W}$

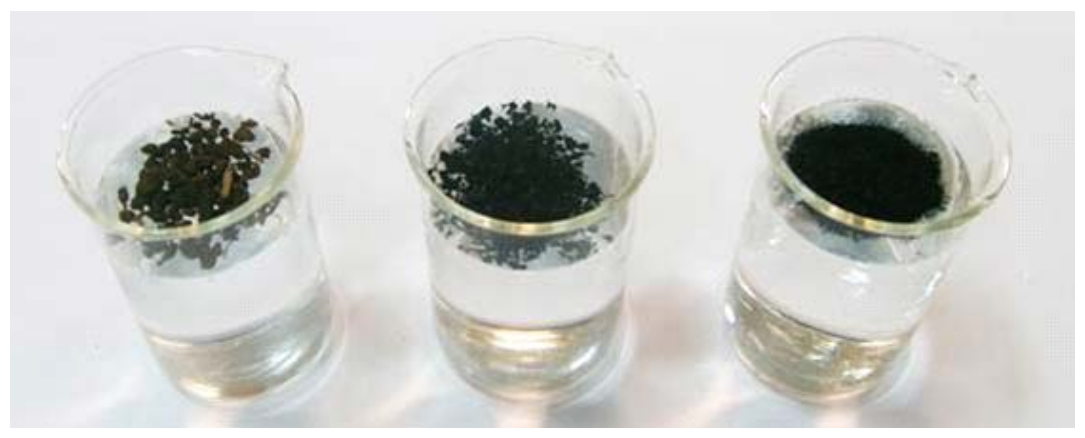

Fig. 7. Photos showing peat buoyancy

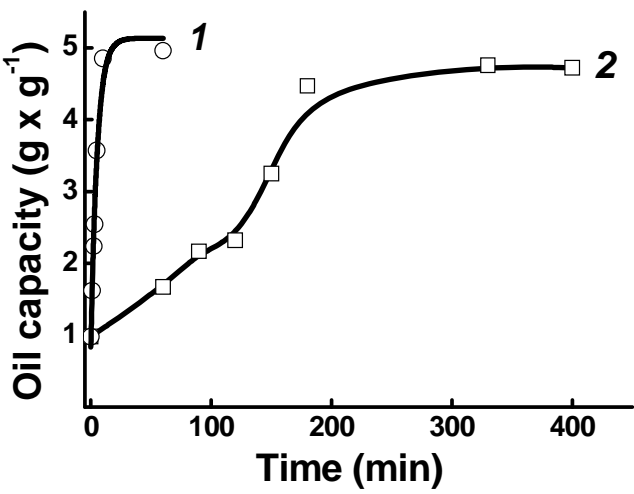

Fig. 8. Dependence of peat's sorbent capacity on the time of carbonization. 1 - microwave carbonization; 2 thermal carbonization. The power of microwave radiation is $700 \mathrm{~W}$. The temperature of thermal carbonization is $600^{\circ} \mathrm{C}$. The heating rate is $10^{\circ} \mathrm{C} \mathrm{min}^{-1} \times$

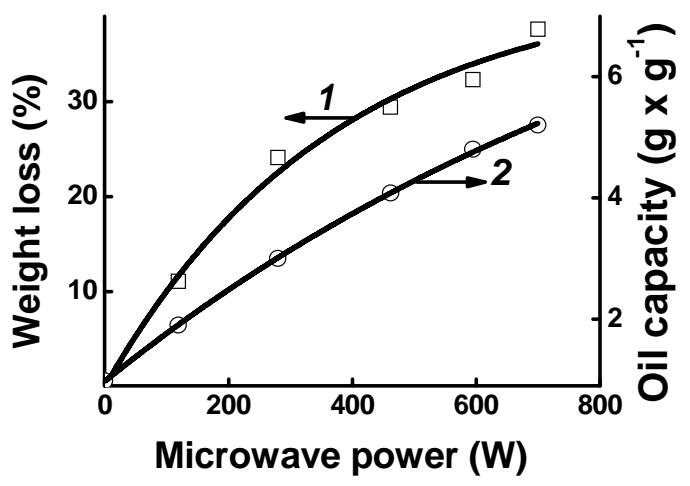

Fig. 9. Dependency of peat carbonization degree (1) and peat sorbent capacity (2) on the power of microwave radiation. The duration of carbonization is $60 \mathrm{~min}$ 
MY molecules - in the main centers, and the molecules of iodine - both on uncharged (hydrophobic) parts of the surface due to dispersion forces, and on partly positively charged areas, due to the fact that in aqueous solutions, molecular iodine is in equilibrium with its ionic forms (Lidin et al, 2000).

On the basis of the data obtained for adsorption of model dyes, it may be concluded that in the process of peat carbonization under the influence of microwave radiation, its porous and chemical structure changes due to pyrolysis of organic compounds, and to the release of pyrolysis gases, resulting in a hydrophobic material.

Due to its hydrophobic properties, carbonized peat features high buoyancy (Fig. 7), which is not less than 30 days (Table 3 ) against 2 to 4 days for initial peat.

To confirm the assumption about increasing hydrophobic properties of peat in the process of carbonization, the influence of carbonization on peat's ability to absorb hydrophobic organic substances like oil and oil products has been studied.

Efficiencies of microwave carbonation and heat carbonization have been compared, and the influence of carbonization time on peat's ability to absorb oil products (sorbent capacity) has been studied.

Peat thermal carbonization was performed according to the following procedure. Into a preliminarily dried in a muffle furnace at $105^{\circ} \mathrm{C}$ for 40 min and weighed ceramic crucible, peat was placed, preliminarily dried to the moisture content of $20 \mathrm{wt}$ \%. The crucible was then closed with a lid and placed into the muffle furnace. The muffle furnace was heated to $600^{\circ} \mathrm{C}$ at the rate of $10^{\circ} \mathrm{C}$ $\mathrm{min}^{-1}$, and the peat was kept at this temperature for 2 hours. The muffle furnace was then switched off, and the closed crucible carbonized peat was left to cool down in the muffle furnace. The crucible with carbonized peat was then removed from the muffle furnace and weighed. The efficiency of carbonization was calculated as the relation of the peat weight loss to the initial weight, expressed in percent. In order to study the kinetics of thermal carbonization of peat using a fixed duration, a closed crucible with a sample of peat was removed from the muffle furnace and placed into a desiccator. After the peat was cooled to the room temperature in the desiccator, the crucible with peat was weighed, and the degree of carbonization was calculated.

The obtained samples of carbonized peat were studied for sorbent capacity (Fig. 8).

As one can see in Fig. 8, in case of microwave carbonization (Fig. 8, curve 1) the maximum sorbent capacity of peat was reached $15-20$ min after it had been treated with microwave radiation. Thermal carbonization of peat (Fig. 8, curve 2) is characterized by slow and gradual increase in the sorbent capacity during carbonization; the maximum sorbent capacity is only achieved after 3 to 3.5 hours. Thus, in order to obtain a sorbent for collecting oil and oil products, microwave carbonization of peat is more efficient than thermal carbonization, primarily due to significantly (10-12 times) reduced duration of the process.

Fig. 9 shows the comparison of carbonation efficiency and peat sorbent capacity. One can see that the dependencies of the carbonization degree (Fig. 9, curve 1) and sorbent capacity (Fig. 9, curve 2) on the power of microwave radiation correlate well.

Table 3 shows the data that characterize carbonized peat as a sorbent for capturing oil and oil products from the surface of the water.

\section{CONCLUSION}

1. It has been established that, as a result of carbonization, the sorbent capacity of carbon sorbent for iodine increases significantly, while it decreases for methylene blue and for methane yellow.

2. It has been established that the carbon sorbent obtained by microwave carbonization of peat is characterized by low moisture content, high buoyancy and oil sorbent capacity.

3. Analysis of the adsorption properties shows that microwave carbonization of peat may be successfully used for obtaining competitive carbon adsorbents for collecting oil and oil products.

\section{ACKNOWLEDGEMENTS}

The work has been financially supported by the Ministry of Education and Science of 
Russia. The unique identifier of applied research (project) is RFMEFI57614X0008.

\section{REFERENCES}

1. Alslaibi, T.M., Abustan, I., Ahmad, M.A., \& Foul, A.A., A Review: Production of Activated Carbon From Agricultural Byproducts Via Conventional and Microwave Heating. Journal of Chemical Technology and Biotechonology, 2013; 7(88):1183-1190.

2. Deng, H., Li, G., Yanga, H., \&Tanga, J., Preparation of activated carbons from cotton stalk by microwave assisted $\mathrm{KOH}$ and $\mathrm{K}_{2} \mathrm{CO}_{3}$ activation. Chemical Engineering Journal, 2010; 163: 373-381.

3. Franca, A.F., Franca, A.F., Oliveira, L.S., Nunes, A.A., \& Alves, C.C.O., Microwave assisted thermal treatment of defective coffee beans press cake for the production of adsorbents. Bioresource Technology, 2010; 101: 1068-1074.

4. Given, P., Spackman, W., Painter, P., Rhoads, C., Ryan, N., Alemany, L., \&Pugmire, R., The fate of cellulose and lignin in peats: an exploratory study of the input to coalification. Organic Geochemistry, 1984; 6: 399-407.

5. Hu, B., Wang, K., Wu, L., Yu, S.-H., Antonietti, M., \&Titirici, M.M., Engineering Carbon Materials from the Hydrothermal Carbonization Process of Biomass. Advanced Materials. Special Issue: Carbon Materials,2010; 7(22): 813-828.

6. Isahak, W.N.R.W., Hisham, M.W.M., \& Yarmo, M.A., Highly Porous Carbon Materials from Biomass by Chemical and Carbonization Method: A Comparison Study. Journal of Chemistry, 2013, Article ID 620346 (6 p) http:/ /dx.doi.org/10.1155/2013/620346.

7. Miura, M., Kagaa, H., Sakurai, A., Kakuchi, T., \& Takahashi, K., Rapid pyrolysis of wood block by microwave heating. Journal of Analytical and Applied Pyrolysis, 2004; 71: 187-199.

8. Alferov, V.V., Physico-chemical study of the regularities of the process of peat pyrolysis in the presence of natural and artificial aluminosilicate materials (Author's abstract from Candidate's thesis, pp. 16), Tver: The Tver State University, 2007.

9. Artemov, A.V., \& Penkin, A.V., Sorption technologies of water purification from oil pollution. Water: Chemistry and Ecology, 2008; 1: $19-25$.

10. Bannova, E.A. Kitaev, N.K., Merkov, S.M., Muchkina, M.V., Zaloznaya, E.P., \& Martynov, P.N., Study of the method of obtaining hydrophobic sorbent based on modified peat.
Sorptive and Chromatographic Processes, 2013; 1(13): 60-68.

11. Belyaev, E.Y., Obtaining and using activated charcoals for environmental purposes. Chemistry of Vegetable Raw Materials, 2000; 2: 5-15.

12. Bogayev, A.V., Lebedev, I.A., Karchevsky, D.F., Berestennikov, D.A., \& Vtorushina, O.O., Obtaining active coals from the shell of pine nuts. Polzunovsky Gazette, 2013; 1: 282-284.

13. Buzaeva, M.V., Kalykova, E.N., \&Klimov, E.S. Absorption properties of activated charcoal AG3 with regard to petroleum products. The Journal of Applied Chemistry, 2010;10(83): 1743-1745.

14. Glazkov, O.V., \& Glazkova, E.À., Oil products adsorption from aqueous emulsions with the use of multilayer adsorbent. Moscow: Petrochemistry, 2001; 65.

15. Golovaty, S.E., Lukashenko, N.K., \& Kovalevich, Z.S., Content of migration-active forms of lead in sod-podzolic and peat soils. Ecological Bulletin, 2010; 3(13): 15-22.

16. Danilov, O.S., Mikheev, V.A., \&Moskalenko, T.E., Microwave processing of solid combustible minerals. The Mining Informational and Analytical Bulletin (scientific and technical magazine), 2010; 3: 203-208.

17. Danilov, O.S., Alternative ways of obtaining activated charcoals. The Mining Informational and Analytical Bulletin (scientific and technical magazine), 2006; 2: 165-169.

18. Danilov, O.S., Mikheev, V.A., \& Moskalenko, T.V., Studying the influence of the electromagnetic microwave radiation on solid fuels. News of the Samara Scientific Center of the Russian Academy of Sciences, 2011; 1-15(13): 1264-1267.

19. Dubinin, M.M., Physico-chemical bases of sorption technology. Moscow - Leningrad: The State Chemico-technical Publishing House, 1932; 385.

20. Kamenshikov, F.A., \& Bogomolny, E.I., Oil sorbents. Moscow-Izhevsk: SIC "Regular and chaotic dynamics”, 2005; 268.

21. Koganovsky, A. M., Klimenko, N. A., Levchenko, T. M., Roda, I. G., Adsorption of organic substances from water. L.: Chemistry, 1990; 256.

22. Koganovsky, A.M., Levchenko, T.M., Roda, I.G., \& Marutovski, R.M., Adsorption technology of wastewater treatment. Kiev: Technics 1981; 175.

23. Kolyshkin, D.A., \& Mikhailova, K.K., Active charcoals. Properties and test methods. Guide Leningrad: Chemistry, 1972; 56. 
24. Kopanitsa, N.O., Kudyakov, A.I. Sarkisov, Y.S. Gorlenko, N.P., \& Kalashnikova, M.À., Rational use of peat in building technologies. Building Materials, 2007; 12: 32-33.

25. Kosov, V.I., Belyakov, A.S., Belozerov, O.V., \& Gogin, D.Y., Peat (resources, technology, geoecology). St. Petersburg: Nauka, 2007; 452.

26. Lidin, R.A., Molochko, B.A., \& Andreeva, L.L., Chemical properties of inorganic substances . Moscow: Chemistry, 2000; 480.

27. Mazlova, E.A., \& Arakcheeva, N.P., Adsorbent for wastewater treatment. Patent No. 2156163, 1999.

28. Placenov, T.G., Galkin, V.A., \& Glushankov, S.L., Carbon adsorbents and their use in industry Moscow: Nauka, 1983; 323.

29. Sirotkina, E.E., \& Novoselova, L.Y., Materials for absorption water purification from oil and oil products. Chemistry for Sustainable Development, 2005; 13: 359-377.

30. Smirnov, A.D., Water sorption purification Leningrad: Chemistry, 1982; 168.

31. Spiridonov, I.G., Vaganov, I.N., \& Pavlusha, A.S. Fossil-organic composite. Patent No. 2477302; 2012.

32. Fellenberg, G., Environmental pollution: Introduction to environmental chemistry . Moscow: Mir, 1997; 232.

33. Feldman, N. Y., Peculiarities of thermal processes in the microwave electromagnetic field. Modern Electronics, 2009; 5: 64-67.

34. Shtin, S.M., Using peat as fuel for small scale power generation. Underground Development of Deposits, 2011; 7: 82-96. 